\title{
ECOLOGICAL AND MORPHOLOGICAL ANALYSIS OF THE CARDIAC INDEX SEASONAL DYNAMICS OF THE CHUVASH REPUBLIC SEDENTARY AND MIGRATORY BIRDS
}

(C) 2019

Repin Denis Vladimirovich, candidate of biological sciences, associate professor of Bioecology and Chemistry Department

I. Yakovlev Chuvash State Pedagogical University (Cheboksary, Russian Federation)

Repina Nadezhda Vasilyevna, candidate of biological sciences, lecturer

Cheboksary Cooperative Technical School of Chuvashpotrebsoyuz (Cheboksary, Russian Federation)

Abstract. The following paper describes the results of seasonal dynamics study of the cardiac index of sedentary and migratory species of the Corvidae birds on the territory of the Chuvash Republic. The objects of the research were sedentary, nomadic and migratory species of the Corvidae birds: magpie, jackdaw, rook and gray crow. The work is based on the materials of the field and laboratory studies, which were conducted in the spring and autumn of 2016-2019 in the Chuvash Republic. The parameters of the cardiac index of grey crows, magpies, rooks and jackdaws were studied and birds with the lowest body mass and the most developed flying muscles, as well as migratory birds had the highest values of this indicator. When determining the cardiac index in spring and autumn, all the considered bird species had significant inter-seasonal differences of the studied parameter. It may be due to seasonal fluctuations in the activity and body mass of the birds. Of all the studied bird species only the rook had the highest seasonal variability of the cardiac index. The magpie had the smallest differences between spring and autumn values of the cardiac index, as they lead the most sedentary lifestyle compared to the rook, the crow and the jackdaw.

Keywords: Chuvash Republic; bird; corvids; hoodie; magpie; rook; jackdaw; cardiovascular system; heart mass; body mass; cardiac index; muscles; synanthropic birds; sedentary bird species; wandering bird species; migratory bird species; ecology; flight; flying activity of birds; seasonal dynamics.

УДК 575.224

DOI 10.24411/2309-4370-2019-12111

Статья поступила в редакцию 19.02.2019

\section{ОЦЕНКА ИНТЕГРАЛЬНОЙ РЕАКЦИИ ЛУКОВ РАЗНЫХ ВИДОВ НА ДЕЙСТВИЕ КСЕНОБИОТИКА ДЛЯ ИСПОЛЬЗОВАНИЯ В ЭКОЛОГО-ГЕНЕТИЧЕСКОМ МОНИТОРИНГЕ}

(C) 2019

Селезнева Екатерина Сергеевна, кандидат биологических наук, доцент кафедры зоологии, генетики и общей экологии

Самарский наџиональный исследовательский университет имени академика С.П. Королёва

$$
\text { (2. Самара, Российская Федераџия) }
$$

Саксонов Сергей Владимирович, доктор биологических наук, профессор, временно исполняющий обязанности директора

Институт экологии Волжского бассейна РАН (2. Тольятти, Самарская область, Российская Федерация)

Аннотация. Для понимания влияния на организмы антропогенных ксенобиотиков, постоянно попадающих в природные экосистемы, необходимы лабораторные модельные эксперименты, в которых используются разнообразные тест-объекты и скрининг-тесты, дающие интегральную оценку биологических ответов. С помощью Allium-теста мы проанализировали реакцию трёх видов рода Allium: Allium cepa, Allium ramosum, Allium fistulosum на воздействие спиртовыми растворами бензотриазола в крайне низких концентрациях 0,0001; 0,001 мг/мл. Растворителем служил 0,5\% изопропиловый спирт. Длительность эксперимента - 5 суток. Выявили, что воздействие бензотриазолом в самой низкой концентрации стимулирует ростовые процессы у A. cера, A. ramosum по сравнению с контролем, в более высокой дозе - ингибирует ростовые процессы. На A. fistulosum бензотриазол в исследованных концентрациях оказывает стимулирующее действие, но в более высокой концентрации оно менее выражено. Раствор бензотриазола в низкой концентрации стимулирует пролиферативную активность в клетках корневой меристемы всех видов. Бензотриазол в более высокой концентрации не стимулирует клеточное деление у $A$. cepa и A. ramosum. У A. fistulosum под действие растворов бензотриазола всегда происходит ингибирование клеточного деления по сравнению с контролем. Наибольшую чувствительность к митозомодифицирующему действию бензотриазола проявляет вид A. fistulosum, у которого бензотриазол вызывает блок на стадии анафазы в двух исследованных концентрациях, у двух других видов воздействие бензотриазолом только в высокой концентрации приводило к торможению митоза на стадии профазы. $A$. ramosum проявляет устойчивость к генотоксичности бензотриазола, а $A$. cepa - высокую чувствительность к мутагенности бензотриазола. Обсуждается связь между адаптационными возможностями и устойчивостью вида к антропогенным ксенобиотикам, а также использованием толерантных видов в качестве тест-объектов для эколого-генетического мониторинга.

Ключевые слова: Allium cepa L.; Allium ramosum L.; Allium fistulosum L.; ксенобиотики; бензотриазол; токсичность; длина корней; прорастание семян; мутагенность; хромосомные аберрации; ана-телофазный анализ; митозомодифицирующее действие; ингибирование; стимулирование; фазы митоза. 


\section{Введение}

Отличительной чертой современной экологии является понимание того, что в окружающую среду постоянно попадают антропогенные ксенобиотики, способные влиять на генофонд организмов, вступивших с ними в контакт. Для оценки состояния окружающей среды проводится эколого-генетический мониторинг, включающий в себя батареи скринингтестов, необходимых для выявления механизмов влияния поллютантов. Это делает подобные исследования дорогими и длительными, поэтому повсеместно используются быстрые тесты, дающие комплексную оценку действия ксенобиотика. К таким тестам относится Allium-тест.

Несмотря на то, что долгое время считалось, что вид Allium сера является эталонным [1, с. 99-112], в руководстве, разработанном Всемирной организацией здравоохранения для Allium-теста, предлагается использовать и другие виды луков рода Allium [2, с. 86-97].

При использовании разных видов рода Allium, в основном обращается внимание на качество семян: их всхожесть и однородность [3, с. 22-27], так как ранее было показано, что со временем в семенах, находящихся в состоянии покоя, наблюдается естественный мутационный процесс [4, с. 206-225].

Работ, посвящённых сравнительному анализу чувствительности разных видов рода Allium немного, а между тем назрела необходимость подбирать виды, в соответствии с задачами мониторинга природных экосистем, как подвергаемых редким воздействиям антропогенных поллютантов, так постоянным из-за нахождения экосистем вблизи с крупными городами и дорогами. В связи с тем, что растения рода Allium часто встречаются в северном полушарии $[5 ; 6$, с. $101-102 ; 7 ; 8$, с. 45-51], где наблюдается максимальная концентрация различных производств и, следовательно, экосистемы постоянно находятся под антропогенным прессом, луки можно было бы использовать в эколого-генетическом мониторинге, сравнивая состояние генофонда природных популяций с результатами лабораторных исследований.

Цель исследования - сравнительный анализ чувствительности видов рода Allium к воздействию спиртовыми растворами бензотриазола в экспериментах с использованием Allium-теста.

Модельным ксенобиотиком выбран бензотриазол, широко применяемый в качестве ингибитора коррозии металлов, светостабилизаторов полимеров [9, с. $1100-1105 ; 10 ; 11$, с. 75-79]. Бензотриазол и его производные проявляют генотоксичность даже в малых дозах. Так японские исследователи обнаружили в природных водоемах производные бензотриазола, которые возникли в результате биохимических превращений азокрасителей, и отметили их мутагенность $[12$, с. $73-80 ; 13$, с. $105-111]$. В ранее проведённых исследованиях мы уже обнаружили мутагенность бензотриазола [14, с. 221-224].

\section{материалы и методы}

Использовали спиртовые растворы бензотриазола в концентрациях 0,0001 и 0,001 мг/мл. Растворителем служил $0,5 \%$ изопропиловый спирт.

Объектами исследования выбраны следующие виды: Allium сера - сорт Стригуновский, Allium ramosum - сорт Джусай, Allium fistulosum - сорт Апрельский. Для всех трёх видов известно число хромосом $(2 \mathrm{n}=16) \quad[15$, с. $700-710 ; 16$, с. $10-11 ; 17$, c. 87-88]. Эксперимент для каждого вида ставился одновременно в трёх повторах. Для этого в три чаш- ки Петри на фильтровальную бумагу, пропитанную 5 мл растворов бензотриазола, помещали по 30 семян. Таким образом, анализировали по 90 семян для каждого вида и для каждой концентрации. Контролем служили семена, проращиваемые в $0,5 \%$ растворе изопропанола, служившего растворителем.

Токсичность оценивали по способности растворов бензотриазола влиять на всхожесть семян и рост корней, цитотоксичность - по способности влиять на пролиферативную активность корневой меристемы, мутагенность - по числу индуцированных хромосомных аберраций с помощью метода ана-телофазного анализа $[18$, с. 23,26$]$.

Митотическую активность клеток корневой меристемы оценивали по величине митотического индекса в промилле, подсчитанного по формуле:

$$
\mathrm{M} И=\frac{\sum(\Pi+\mathrm{M}+\mathrm{A}+\mathrm{T}) \times 1000}{\sum(И+\Pi+\mathrm{M}+\mathrm{A}+\mathrm{T})},
$$

где $\Pi$ - число клеток на стадии профазы, $M$ - число клеток на стадии метафазы, $A$ - число клеток на стадии анафазы, $T$ - число клеток на стадии телофазы, $U$ - число клеток на стадии интерфазы.

Относительную продолжительность фаз митоза, характеризующую митозомодифицирующее действие ксенобиотика, рассчитывали в процентах по формуле:

$$
\mathrm{X}(\%)=\frac{\sum \mathrm{X}}{\sum(\Pi+\mathrm{M}+\mathrm{A}+\mathrm{T})} \times 100 \%,
$$

где $X$ - определенная фаза митоза ( $П$ - профаза, $M$ метафаза, $A$ - анафаза, $T$ - телофаза), таким образом при сравнении с контролем можно обнаружить способность соединений останавливать деление на определенной стадии митоза.

Исследовали не менее 1000 клеток для анализа пролиферативной активности в каждой серии экспериментов, для каждого вида. Для оценки мутагенности анализировали не менее 300 ана-телофаз.

Достоверность различий в чувствительности исследуемых видов луков к воздействию растворов бензотриазола оценивали с помощью двухфакторного дисперсионного анализа [19, с. 159-179].

\section{Результаты и обсуждение}

Обычно в токсикологических и генетических экспериментах оценивают действие ксенобиотика в высоких дозах: $\mathrm{LD}_{50}, \mathrm{LD}_{30}$. Однако использование таких доз не позволяет выявить как различия в чувствительности между видами, так и механизмы действия соединений. Использование малых доз позволяет изучить не только ингибирующее воздействие, но и стимулирующее, иногда оказываемое ксенобиотиком. Природа стимулирующего действия малых доз генотоксикантов мало изучена. Между тем, стимуляция жизненных процессов в среде, загрязняемой потенциально токсичными соединениями, может вызвать необычные экологические последствия, и должна приниматься во внимание при установлении регламентов качества среды, а также может быть использована в качестве инструмента для управления биологическими сообществами. В связи с этим в модельных экспериментах мы использовали очень низкие дозы бензотриазола.

Изучая воздействие спиртовых растворов бензотриазола на организменном уровне, мы исследовали такие показатели как процент проросших семян и среднюю длину корней и сравнивали результаты с контрольными (см. табл. 1). 
Селезнева Е.С., Саксонов С.В.

Оценка интегральной реакции луков разных видов на действие ксенобиотика..

03.02.00 - общая биология

Таблица 1 - Реакция разных видов рода Allium на воздействие спиртовыми растворами бензотриазола

\begin{tabular}{|l|c|c|c|c|c|c|}
\hline \multirow{2}{*}{ Тип воздействия } & \multicolumn{3}{|c|}{ Прорастание семян, \% } & \multicolumn{2}{c|}{ Ср. длина корней лука на 5 день роста, мм } \\
\cline { 2 - 8 } & A. ramosum & A. cepa & A. fistulosum & A. ramosum & A. cepa & A. fistulosum \\
\hline Контроль & 59 & 74 & 79 & 14 & 15 & 18 \\
\hline Бензотриазол 0,0001 мг/мл & 64 & 82 & 88 & 15,2 & 25,3 & 27,4 \\
\hline Бензотриазол 0,001 мг/мл & 54 & 70 & 82 & 12,4 & 17,2 & 18,4 \\
\hline
\end{tabular}

Как видно из полученных результатов, раствор бензотриазола в самой низкой концентрации 0,0001 мг/мл оказывает стимулирующее действие по сравнению с контролем, увеличивая число проросших семян и длину корней на 5 день роста. Более высокая доза бензотриазола ингибирует рост, но не у всех видов, а только для A. сера, A. ramosum. На A. fistulosum бензотриазол в двух исследованных концентрациях оказывает стимулирующее действие. Необходимо отметить, что стимуляция ростовых процессов при воздействии более высокой концентрацией менее выражено, чем низкой. Проведённый двухфакторный дисперсионный анализ показал, что выявленные различия достоверны $(\mathrm{p}<0,01)$.

Чтобы выяснить причину стимуляции ростовых процессов, мы исследовали пролиферативную активность в клетках корневой меристемы луков, потому что изменение пролиферативной активности в опыте по сравнению с контролем является показателем цитотоксичности исследуемых растворов.

Результаты действия спиртовых растворов бензотриазола на митотическую активность клеток представлены на рис. 1.

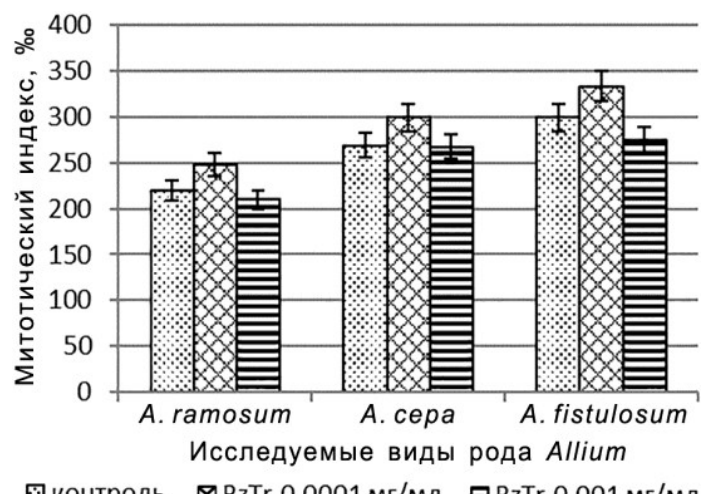

凤контроль $\otimes \mathrm{Bz} \operatorname{Tr} 0,0001 \mathrm{mr} / \mathrm{mл}$ 日BzTr 0,001 мг/мл

Рисунок 1 - Показатели

пролиферативной активности клеток корневой меристемы луков разных видов

Проведённый двухфакторный дисперсионный анализ показал, что все виды достоверно различаются в реакции клеток корней меристемы на воздействие бензотриазола ( $<<0,001)$. Растворы бензотриазола в низкой концентрации стимулируют пролиферативную активность в клетках корневой меристемы всех видов, но сильнее всего у A. fistulosum. Оказалось, что клетки меристемы $A$. сера и $A$. ramosum не чувствительны к действию раствора бензотриазола в более высокой концентрации, в отличие от A. fistulosum, у которого происходит ингибирование клеточного деления по сравнению с контролем.

Чтобы понять митозомодифицирующее действие растворов бензотриазола в разной концентрации, мы проанализировали относительную продолжительность фаз митоза (см. рис. 2).

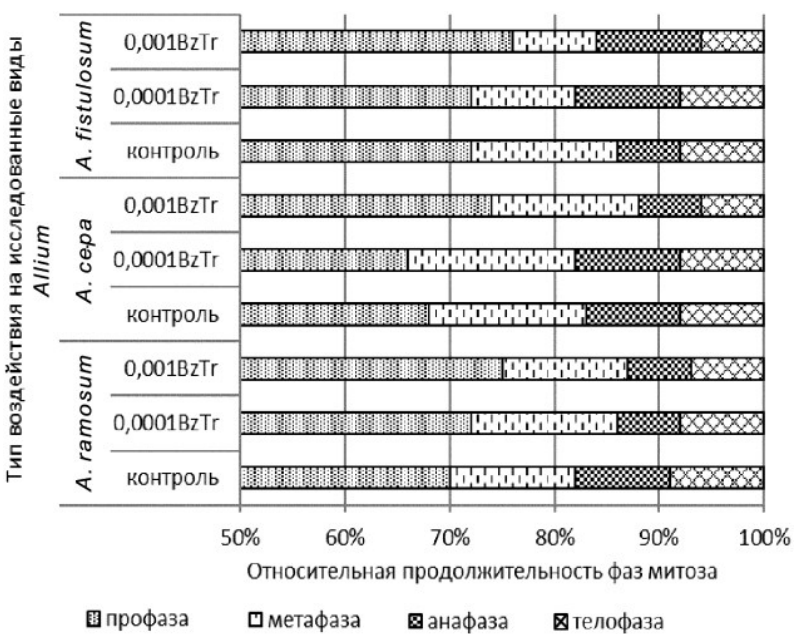

Рисунок 2 - Митозомодифицирующее действие растворов бензотриазола в разных концентрациях на клетки корневой меристемы исследуемых видов лука

Полученные результаты показывают, что из всех анализируемых видов лука, только клетки меристемы A. fistulosum проявили специфическую чувствительность к воздействию бензотриазола, демонстрируя блок на стадии анафазы независимо от концентрации раствора, что косвенно подтверждается большим количеством аберраций типа «мост», индуцированных бензотриазолом. В клетках меристемы A. сера и A. ramosum обнаруживается блок на стадии профазы только при действии бензотриазолом в более высокой концентрации. Возможно у этих видов более эффективные системы репарации. Многие генотоксиканты демонстрируют митозомодифицирующее действие, увеличивая относительную продолжительность стадии профазы [20, с. 93-98; 21, с. 2125], что говорит о способности этих соединений вмешиваться в синтез предшественников ДНК.

Наблюдаемое митозомодифицирующее действие указывает на генотоксичность растворов бензотриазола в выбранных концентрациях.

Анализ мутагенности бензотриазола для исследуемых видов показал, что у двух видов: А. сера и A. fistulosum возникают аберрантные ана-телофазы следующих типов: «мосты», «отставания» «обломки», у A. ramosum - только «отставания» и «обломки». Однако у A. fistulosum большую часть представляют собой мутации типа «простые мосты», «двойные мосты», у A. сера - часто встречаются микроядра и фрагментация хромосом, никогда не встречающиеся у A.fistulosum и A. ramosum. $У$ A. ramosum хромосомные аберрации встречаются крайне редко, как в опыте, так и в контроле.

Результаты анализа чувствительности луков разных видов к мутагенному действию бензотриазола суммированы на рис. 3. 


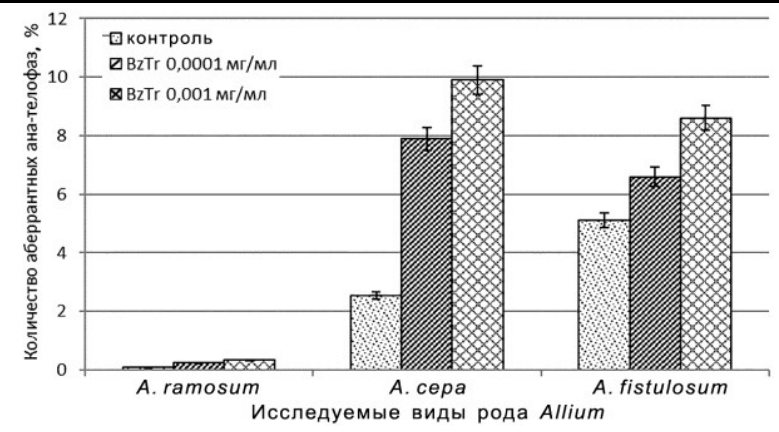

Рисунок 3 - Количество аберрантных ана-телофаз в клетках корневой меристемы индуцированных спиртовыми растворами бензотриазола у трех видов рода Allium

Проведённый двухфакторный дисперсионный анализ показал достоверное различие в чувствительности к мутагенному воздействию бензотриазола у исследованных видов рода Allium $(\mathrm{p}<0,001)$. Минимальную чувствительность к мутагенному действию бензотриазола проявил $A$. ramosum, максимальную - A. сера.

Мы попытались разобраться в полученных результатах. Используемые нами концентрации очень малы, мы их выбрали в связи с тем, что очень часто в природных экосистемах остаются следовые дозы ксенобиотиков. Создав модель такого действия, мы получили парадоксальные результаты - стимуляцию некоторых процессов самой низкой дозой. Такого рода явление, описано ранее и получило название гормезис, представляющего собой двухфазную зависимость доза-эффект, при которой низкие дозы воздействующего фактора оказывают стимулирующее влияние на биологический объект, а высокие дозы - ингибирующее [22, с. 627-630]. В настоящее время механизмы и закономерности, лежащие в основе немонотонных ответов организмов, остаются неизвестными [23, с. 508-604]. Существует большое количество различных гипотез [24, с. 693-703], но большинство исследователей считают, что парадоксальные эффекты имеют адаптивный характер. Стимулирующий эффект гормезиса предлагают рассматривать как явление сверхкомпенсации, то есть избыточной активации защитных систем организма [25, с. 594-617]. Мы это наблюдали при анализе митозомодифицирующего действия раствора бензотриазола в самой низкой концентрации у двух видов: A. ramosum и $A$. cepa.

К сожалению, в экологии проблеме гормезиса уделяется крайне мало внимания, хотя этот феномен очень важен для решения прикладных задач. До сих пор в фитоиндикации при выборе параметров организма растений, пригодных для оценки уровня загрязнения окружающей среды, не учитывается возможность парадоксального эффекта действия изучаемого фактора, что может привести к неадекватной оценке реакции тест-объекта. Следовательно, только подбор методов, позволяющих дать интегральную оценку действия факторов, позволит разобраться в реакции организмов на антропогенный фактор.

Исследуя экосистемы, подвергшиеся антропогенному воздействию, в мониторинговых исследованиях важно использовать методы, позволяющие дать интегральную оценку видов, избранных в качестве тестобъектов. Безусловно, дикие виды рода Allium, широко распространенные в природе, могут быть использования для первичного тестирования состояния экосистем, но даже у растений одного рода существуют виды с высокой толерантностью к ксенобиотикам и виды чувствительные к ним [26, с. 84-88; 27], что также следует учитывать в мониторинговых исследованиях.

Виды рода Allium имеют большое биоресурсное значение: декоративное, пищевое, лекарственное, медоносное. Испытывая постоянное негативное воздействие антропогенной природы, луки успешно сопротивляются ему за счёт высокой экологической валентности, связанной с генетически закрепленным полиморфизмом, и способны дать адаптивный ответ $[28$, с. 93-109]. Последнее позволяет использовать некоторые виды для изучения механизмов адаптации. Возможно, в эколого-генетическом мониторинге необходимо использовать дикие виды в сочетании с видами, давно культивируемыми человеком и используемыми в Allium-тесте, дающем интегральную оценку реакций организмов на ксенобиотики.

\section{Заключение}

Проведённый нами анализ интегральной реакции луков разных видов на генотоксическое действие бензотриазола в низких дозах выявило нецелесообразность использования $A$. ramosum в качестве тестобъекта для Allium-тестов, используемых в экологогенетическом мониторинге. Для соединений со слабой токсичностью можно использовать A. fistulosum, крайне чувствительного к митозомодифицирующему действию, A. сера можно использовать для анализа мутагенности общего загрязнения окружающей среды.

\section{Список литературы:}

1. Fiskesjo G. The Allium Test as a standard in environmental monitoring // Hereditas. 1985. Vol. 102. P. 99112

2. Руководство по краткосрочным тестам для выявления мутагенных и канцерогенных химических веществ // Гигиенические критерии состояния окружающей среды. Всемирная организация здравоохранения. Женева, 1989. № 51.212 с.

3. Зотов А.В., Иванова М.В. К перспективам применения видов и сортов лука в процедуре Alliumтеста // Вестник молодых ученых и специалистов Самарского государственного университета. 2014. № 2. C. 22-27.

4. Орлова Н.Н. Естественный мутационный процесс в семенах при хранении // Успехи современной генетики. 1972. Т. 4. С. 206-228.

5. Булах П.Е. Луки природной флоры Средней Азии и их культура на Украине. Киев: Наукова думка, 1994. 123 с

6. Серегин А.П. Новые комбинации в роде Allium L. (Alliaceae) // Новости систематики высших растений. 2004. Т. 36. С. 101-102.

7. Серегин А.П. Род Allium L. (Alliaceae) во флоре Восточной Европы: дис. ... канд. биол. наук. М., 2007. $242 \mathrm{c}$.

8. Серегин А.П. Флористические материалы и ключ по лукам (Allium L., Alliaceae) Европейской России // Бюл. МОИП. Отд. биол. 2005. Т. 110, вып. 1. С. 45-51.

9. Кузнецов Ю.И., Андреева Н.П., Агафонкина М.О. Адсорбция и защитные свойства 1,2,3-бензотриазола на сплаве МНЖ 5-1 в нейтральных растворах // Электрохимия. 2014. Т. 50, № 10. С. 1100-1105.

10. Наметкин С.С. Гетероциклические соединения. М.: Наука, 1981. 356 с.

11. Шемаханская М.С. Реставрация металлов. Методические рекомбинации. М.: ВНИИР, 1989. 108 с.

12. Nukaya H., Shiozawa T., Tada A., Terao Y., Ohe T., Watanabe T., Takahashi Y., Asanoma M., Sawanishi H., Katsuhara T., Sugimura T., Wakabayashi K. Identificati- 
on of 2- [2-(acetylamino)-4-amino-5-methoxyphenyl]-5amino-7-bromo-4-chloro-2H-benzotriazole (PBTA-4) as a potent mutagen in river water in Kyoto and Aichi prefectures, Japan // Mutat. Res. 2001. Vol. 492. P. 73-80.

13. Shiozawa T., Suyama K., Nakano K., Nukaya H., Sawanishi H., Oguri A., Wakabayashi K., Terao Y. Mutagenic activity of 2-phenylbenzotriazole derivatives related to a mutagen, PBTA-1, in river water // Mutation Research. 1999. Vol. 442 (2). P. 105-111.

14. Селезнева Е.С., Валиева Э.А., Теньгаев Е.И. Роль структуры ксенобиотика в развитии биологического ответа на примере производных бензотриазола // Вестник Самарского университета. Естественнонаучная серия. 2012. № 3-1 (94). С. 212-225.

15. Бахтина Л.И. Числа хромосом некоторых видов рода Allium (Alleaceae) флоры CССР // Ботанический журнал. 1985. Т. 70, № 5. С. 700-710.

16. Иксакова А.И. Оценка и отбор материала для селекции многолетних луков в условиях нечерноземной зоны России: автореф. дис. ... канд. с/х. наук. M., $2011.20 \mathrm{c}$.

17. Песня Д.С., Романовский А.В., Прохорова И.М. Исследование токсического и генотоксических эффектов синтетических пищевых красителей методом Allium test // Ярославский педагогический вестник. Естественные науки. 2012. Т. III. № 3. С. 86-93.

18. Прохорова И.М., Фомичёва П.Н., Ковалёва М.И. Оценка митотоксического и мутагенного действия факторов окружающей среды. Методические указания. Ярославль: ЯрГУ, 2003. 140 с.

19. Лакин Г.Ф. Биометрия. М.: Высшая школа, 1990. $352 \mathrm{c}$.

\section{ASSESSMENT OF THE INTEGRATED REACTION OF ONIONS OF DIFFERENT TYPES FOR THE ACTION OF XENOBIOTICS FOR USE IN ECOLOGICAL-GENETIC MONITORING} (C) 2019

Selezneva Ekaterina Sergeevna, candidate of biological sciences, associate professor of Zoology, Genetics and General Ecology Department Samara National Research University (Samara, Russian Federation)

Saksonov Sergey Vladimirovich, doctor of biological sciences, professor, acting director Institute of Ecology of Volga River Basin of Russian Academy of Sciences

(Togliatti, Samara Region, Russian Federation)

Abstract. The influence of many anthropogenic xenobiotics constantly falling into natural ecosystems is poorly understood, so laboratory experiments are needed to understand the consequences of such actions. It is especially important to study this effect on plants that are unable to avoid uncomfortable conditions. It is necessary to use a variety of test objects and screening tests that give an integral assessment of biological responses. Such tests include the Allium-test, which allows to evaluate toxicity at both the organismic and cellular levels, as well as mutagenicity of xenobiotics. We analyzed the response of three species of the genus Allium (Allium cepa, Allium ramosum, Allium fistulosum) to exposure to alcohol solutions of benzotriazole in extremely low concentrations. This heterocyclic compound is widely used in industry as a light stabilizer for polymers and as an anti-corrosion agent protecting various metals and alloys. The biological activity of two concentrations $(0,0001 ; 0,001 \mathrm{mg} / \mathrm{ml})$ was studied. The solvent was $0,5 \%$ isopropyl alcohol. Allium test was used to analyze a biological response of the selected onions. The duration of the experiment was 5 days. The effect of benzotriazole stimulated growth processes in $A$. cepa and A. ramosum in the lowest concentration and inhibited growth processes in a higher dose compared to the control. Benzotriazole had a stimulating effect on A. fistulosum in both of the concentrations studied, however, the stimulating effect in a high concentration was less pronounced. The solution in low concentration stimulates the proliferative activity in the cells of the root meristem of all species. However, cells of A. cepa and A. ramosum meristem are not sensitive to the action of a higher concentration of benzotriazole solution, unlike $A$. fistulosum, in which cell division is inhibited in comparison with the control. It was found that A. fistulosum, in which benzotriazole causes a block at the anaphase stage in both concentrations studied, is the most sensitive to the mitosis-modifying action of benzotriazole. In the other two species, only exposure to benzotriazole in high concentration led to inhibition of mitosis at the prophase stage. A. ramosum is resistant to the genotoxicity of model xenobiotics, and $A$. cepa is highly sensitive to benzotriazole mutagenicity. The paper discusses the relationship between the adaptive capabilities of a species and its resistance to anthropogenic xenobiotics, as well as the use of tolerant species as test objects for ecological genetic monitoring.

Keywords: Allium cepa L.; Allium ramosum L.; Allium fistulosum L.; xenobiotics; benzotriazole; toxicity; root length; seed germination; mutagenicity; chromosomal aberrations; ana-telophase analysis; mitosis modifying action; inhibition; stimulation; phases of mitosis. 